\title{
ЛОКУС КОНТРОЛЯ НАСЕЛЕНИЯ ГРУЗИИ В УСЛОВИЯХ ПАНДЕМИИ COVID19
}

\author{
Бжалава Т.И., Имедадзе И.В., Сакварелидзе Р.Т., Цулукидзе А.Г. (Центр \\ Исследования и Коррекции Психлологической Установки (ТГМУ), Институт \\ Общественных Дел Грузии (GIPA), Тбилиси, Грузия) \\ bjalava@yahoo.com,irimedi@yahoo.com,sakramaz@yahoo.com, \\ tsulukidzeana8@gmail.com

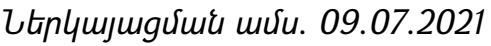 \\ 9pmpunuर्जuध uर्रu. 09.08.2021

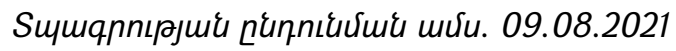

Одним из факторов, влияющих на поведение в условиях пандемии COVID 19 и в свою очередь, отвечающих на эти условия, является локус контроля. Цель представленного исследования - определить локус контроля в условиях пандемии и узнать, как воздействует стрессовая ситуация на тип локуса контроля. Исследование проводилось с помощью стандартизированного и валидного теста Роттера (адаптированного для исследования населения Грузии) и модифицированную версию того же теста (Р.Т. Сакварелидзе) со ссылкой на пандемию в каждом утверждении теста. Участников тестировали используя обе версии теста.

Главный результат исследования указывает на то, что в условиях пандемии люди склонны менять свой локус контроля - в большинстве случаев они становятся более интерналами, чем были раньше. Исследование также показало, что в ряде случаев происходит замена экстернального локуса на интернальный. Такое изменение локуса контроля способствует повышению персональной ответственности в выполнении рекомендаций специалистов медицинской области. Исходя из этого, рекомендации психологов должны продвигать и поощрять качества характерные для интерналов. Полученные данные будут полезны при разработке стратегии психо-коррекции и психо-реабилитации в условиях пандемии и в пост-пандемический период.

Ключевые слова: пандемия COVID-19, локус контроля, тест Pоттера и его модифицированная версия.

DOI: https://doi.org/10.46991/SBMP/2021.4.2.121

Масштабы, уровень опасности и влияние на общество пандемии COVID19 настолько велики, что не могли не сказаться на возникновении достаточно серьезных психологических проблем. Существование этих проблем уже 
подтверждено исследованиями. Их число несомненно увеличится, т.к. с этой глобальной эпидемией связан очень широкий круг психологических проблем. Можно сказать, что пандемия стала настоящим вызовом для психолологической науки, чтобы она проявила свой реальный практический потенциал.

И действительно, за последнее время появляется всё больше публикаций о психологических особенностях людей, попавших в условия COVID-пандемии. Большинство психологических исследований указывают на выраженную тревожность, депрессию, растерянность, отчаяние среди населения различных стран. В результате повышенной тревожности авторы фриксируют патологические проявления, которые выражаются неорганизованным и дезадаптивным поведением, паникой, суицидальными мыслями и другими расстройствами. Такой высокий уровень тревоги вызван не только страхом перед заражением вирусом, но и существованием многочисленных внешних факторов, управлять которыми человек может в меньшей степени. Эти факторы - неуверенность в возможности получить полноценное медицинское обслуживание, нехватка средств защиты, вероятность, что медицинский персонал находится в состоянии выгорания (burnout), экономическое положение в будущем и др.

Уникальность настоящей ситуации состоит в том, что пандемия коснулась и поразила все сфреры жизнидеятельности человека - работу, отдых, спорт, приём пищи и т.д. Всё это вызывает «чувтсво полной беззащитности человека перед опасностью» [10, с.33-48].

В Грузии, как и в большинстве стран мира, были установлены ограничения в ответ на пандемию. По всей территории Грузии были объявлены чрезвычайное положение и комендантский час. Эти изменения коснулись всего населения. Они отразились на их социально-экономическом и, естественно, психологическом состоянии. Именно поэтому, нас интересует, насколько повлияло вызванное пандемией изменение ситуации на психологический статус человека, в частности, на локус контроля (усиление или ослабление существующего локуса, или полное его изменение).

B стрессогенной ситуации, вызванной COVID-пандемией, величайшее значение придаётся тому, насколько справится человек с этой ситуацией и сможет ли выйти из неё с наименьшими т.н. психологическими потерями. Это прямо зависит от психологических характеристик личности - какую личность настигла пандемия и как отразилась на ней. Общеизвестно, что во время эпидемий уязвимость людей, наряду с био-медицинскими факторами, в значительной степени обусловлена актуальным психологическим состоянием индивида (стресс, тревога, отчаяние, капитулянтный настрой и др.). Вероятность возникновения этих состояний и их интенсивность, в свою очередь, зависит от личностных качеств. В этой связи важны параметры локуса 
контроля, который представляет собой тенденцию человека, возложить ответственность на внешние события, внешние силы (внешний локус контроля - экстернальность) или на собственные возможности и усилия (внутренний локус контроля - интернальность). Понятие локуса контроля ввёл Джулиан Роттер в 1954 г. Он отмечает, что интерналы уверены в себе, последовательны в достижении целей, уравновешенны, дружелюбны и независимы. В отличие от них, склонные к внешней локации контроля (экстерналы), проявляют неопределённость, неуравновешенность, тревожность, подозрительность и агрессивность.

Мы поставили целью, исследовать локус контроля людей в условиях пандемии; узнать, меняет ли созданная пандемией стрессогенная ситуация локус контроля личности. Для этого использовали адаптированный для населения Грузии, стандартизированный и валидизированный тест локуса контроля предложенный Роттером [7, с. 16-25] и вариант теста Роттера, предложенный Р.Т.Сакварелидзе, где в перечисленных утверждениях теста вставлен COVID-19. Каждый респондент заполнял оба варианта теста Роттера. Тем самым, мы стремились выявить, как воздействует фрактор COVID-19 на локус контроля респондента - меняется ли он количественно, по степени своей выраженности в рамках прежнего типа локуса, или радикально изменяет направление локуса контроля.

«Локус контроля может влиять не только на то, как мы реагируем на происшествия в нашей жизни, но и на мотивацию осуществления действий. Если вы верите, что обладаете ключом своей судьбы, в большей степени будете принимать меры для изменения ситуации при надобности. С другой стороны, если вы думаете, что результат не зависит от вас, вы меньше будете пытаться работать над изменениями» $[3,1]$.

Основная гипотеза проведённого эмпирического исследования сформировалась следующим образом: пандемия COVID-19 способствовала изменениям локуса контроля (имеется в виду как радикальное изменение типа локуса, так и тенденция роста или снижения его показателей).

В исследовании принимали участие 204 респондента. Среди них - 150 женщин и 54 мужчин. Участники эксперимента делятся на три возрастные группы: 16 лет, 17-25 и 26-50 лет. Опрос производился через социальные сети в период пандемии (март-май 2020 года). Респонденты были подобраны по единственному, возрастному критерию. Возраст не превышал 50 лет, т.к. люди преклонного возраста в меньшей мере пользуются соцсетями. Исследование было количественным. Для заполнения опросника предполагалось 15-20 минут.

В исследовании, локус контроля оценивался по шкале измерения локуса контроля Роттера. Шкала требует от респондента выбрать из двух, «А» и «Б» утверждений, одно - описывающее внутренний (интернальный) локус контроля 
или наружный (экстернальный) локус контроля. При помощи ключа опросника, каждое утверждение оценивается определённым количеством баллов. После суммирования баллов, с помощью программы “Ехсеl” вычислялись процентные показатели. Показатели выше 50\% указывают на экстерналов, а ниже 50\% - на интерналов. Низкая оценка соответствует внутреннему локусу контроля (человек причиной последствий событий в его жизни считает себя), а высокий процентный показатель указывает на внешний локус контроля (причиной последствий собственного поведения считают судьбу, случай или действия людей, имеющих власть). Респонденты выбирали из двух противоположных утвеждений тот, с которым соглашались полностью или в большей степени. Опросник определяет личностное кредо, взгляды человека на причины жизненных явлений.

Шкала состоит из 29 пар утверждений, из них 23 измеряют непосредственно локус контроля, а 6 пар являются заполняющими утверждениями.

В исследовании также применялся модифицированный профессором Р.Т.Сакварелидзе тест Роттера для измерения локуса контроля с учётом COVID19. В утверждениях теста Роттера вставлен COVID19. Каждый респондент заполнял оба теста.

В начале опросника были заданы вопросы для установления возраста и пола. На всякий случай, производилась идентификация личности по электронной почте. Сперва респондент заполнял тест Роттера, определяющий общий локус коннтроля, а после - тот же тест, модифицированный с учётом COVID19. Сравнивали данные тестов общего и COVID-локуса контроля каждого респондента, с целью выявить, как повлияла ситуация COVID19 на локус контроля респондента - остался ли он прежним, но с изменённой силой или полностью изменилось направление локуса.

В инструкции указывалось, что респонденты не должны долго обдумывать ответы. Тесты общего и COVID-локуса контроля были объединены в один вопросник, чтобы была возможность установить корреляцию между данными тестов общего и COVID-локуса контроля каждого респондента. Чтобы отвлечь внимание респондентов и заодно, получить дополнительные данные, между этими двумя тестами, мы поместили два вопроса - как, по мнению респондентов, им удавалось справляться со стрессовыми ситуациями до появления COVID19 и как они справляются сейчас со стрессовой ситуацией, вызванной пандемией COVID19. Ответы оценивались по 7 бальной шкале.

Корреляцию между разными переменными проверяли с помощью программы SPSS. Наряду с этим, вычислили частоту каждой переменной и с помощью разных тестов (anova, independent t test) установили определённые связи: различие между общим локусом контроля и локусом контроля при COVID19, корреляция между умением управлять ситуационным стрессом и 
изменением локуса контроля, корреляция между умением управлять стрессом, вызванным пандемией и изменением локуса контроля, связь между умением управлять стрессом и радикально изменённым локусом контроля, радикальное именение локуса контроля с учётом пола, радикальное изменение локуса контроля по ворастным группам, различия с учётом переменной возраста, различия между группами по полу, корреляция между стрессом и типами локуса контроля. Была проверена основная гипотеза и измерена валидность инструментов исследования.

Что касается достоверности инструментов исследования: показатель достоверности теста общего локуса контроля - Cronbach's Alpha=0.684. Показатель достоверности теста локуса контроля адаптированного к COVIDпандемии - Cronbach's Alpha=0.735, что указывает на достоверность в обоих случаях. Так как мы хотели узнать, есть ли разница между “общим» и «ковид» локусами контроля в ситуации пандемии (имеется в виду как радикальное изменение типа локуса контроля, так и тенденция роста или уменьшения его показателя), мы сравнили между собой средние баллы тестов общего и адаптированного к COVID-пандемии локусов контроля. Для вычисления разницы между локусами контроля мы разработали отдельную новую переменную - EL- diff и IL-diff, которая фриксировала разницу между баллами теста общего локуса контроля и теста локуса контроля с COVID-19. Оказалось, что разница между баллами общего локуса контроля и коронавирусного локуса контроля составляет 12 баллов. Мы определили средние баллы обоих тестов общего и «с COVID-19». Сравнили отдельно показатели экстернальности в двух тестах и отдельно - показатели интернальности. По показателям теста общего локуса контроля средний балл экстернальности 46.9, а по тесту с COVID19-34.6. Средний показатель интернальности по тесту общего локуса контроля 53.0, а по тесту «с COVID19»-65.3.

Показатели радикального изменения локуса контроля респондентов распределились следующим образом: 28\% стали интерналами, 4\% стали экстерналами, в 68\% случаев радикальное расхождение между локусами контроля не фриксируется. Кроме того, оказалось, что по баллам, в «COVIDтесте» меньше экстернальности и больше интернальности. Наиболлее важным является то, что подтвердилась наша гипотеза - под влиянием пандемии COVID-19 произошли изменения локуса контроля (имеется в виду как радикальное изменение типа локуса контроля, так и тенденция роста или снижения его показателей). Sig.(2-tailed)<0,05, что позволяет сделать вывод, что разница между общим и COVID-локусами контроля, фриксированная в средних баллах, является статистически значимым.

Следует отметить, что не подтвердилась значимая корреляция между управлением ситуационного стресса и изменением локуса контроля (Correlation 
Coefficient 0-0.2). Шкала стресса не находится в корреляции ни с чем - по отдельности сравнивались связь ситуационного стресса и связанного с пандемией стресса с изменениями типов локуса контроля (экстернальностьинтернальность). Согласно полученным данным, не подтвердилась корреляция между показателями стресса и типами локуса контроля - в обоих случаях sig $>0.05$.

Заключение: основные результаты проведённого эмпирического исследования показали, что в условиях пандемии у людей меняется локус контроля - в большинстве случаев, они становятся более интернальными, чем были. Также отметились случаи радикального изменения от экстернальности к интернальности. Как оказалось, в ситуации пандемии COVID19 локус контроля меняется от экстернальности к интернальности. Это указывает на то, что граждане с большей ответстенностью отнесутся к выполнению рекомендаций специалистов соответствующей медицинской сферы. Исходя из этого, со стороны государственных структур и медицинских работников, наравне с другими рекомендациями, нужно усилить агитацию характерных черт интернальности. Это прямой путь к предотвращению распространения пандемии.

\section{Литература}

1. Bonanno G. A. et al. Psychological resilience and dysfunction among hospitalized survivors of the SARS epidemic in Hong Kong: a latent class approach. Health Psychology, 27(5), 2008, pp.659-67.

2. Cherry K. Locus of Control and Your Life. Verywellmind, 2019.

3. Jeronimus B. Personality and the Coronavirus COVID-19 Pandemic. In book: Happy Neurotics. University of Groningen, 2020.

4. Lake J. Locus of Control and COVID-19. Psychology Today, 2020.

5. Qiu J. et al. A Nationwide Survey of Psychological Distress among Chinese People in the COVID-19 Epidemic: Implications and Policy Recommendations, 2020.

6. Tansheng L., Changdeog, H. The Protective Effects of Resilience on COVID-19 Stress. In: The Journal of Humanities and Social Sciences 21, 2020 vol. 11. No 1.1. The Academy of Asian Cultural Studies.

7. Sumbadze, N., Qitiashvili, A., Pirtskhalava, E., Maisuradze, M. (2012). Social research methods. ENPAK. 16-25. (In Georgian)

8. Wallston B. S., Wallston K. A. Locus of control and health: A Review of the literature. Health Education Monographs 1978, pp. 1-9.

9. Wu P. et al. The psychological impact of the SARS epidemic on hospital employees in China: Exposure, risk perception, and altruistic acceptance of risk. Canadian Journal of Psychiatry, 54(5), 2009, pp. 302-311. 
10. Stankovska G., Memedi I., Dimitrovski D. Coronavirus covid-19 disease, mental health and psychosocial support. Society Register, 4(2), 2020, pp. 33-48.

https://doi.org/10.14746/sr.2020.4.2.03

\section{LOCUS OF CONTROL IN GEORGIAN POPULATION WHILE THE 2020 CORONAVIRUS PANDEMIC}

Bzhalava T. I., Imedadze I. V., Sakvarelidze R. T., Tsulukidze A. G. (GIPA, Tbilisi, Georgia)

One of the factors affecting the behaviour in the conditions of COVID19 pandemic and, in its turn, responding these conditions, is the locus of control. Presented study aims to identify the locus of contol in pandemic situation and explore whether the stressful situation will affects the locus control type. The research uses an adapted (for Georgian population), standardized and validated Rotter Test and its modified version (by R. Sakvarelidze) where reference to the pandemic appears in every statement of the test. The subjects were tested using both versions.

Main result of the study shows that in pandemic conditions people tend to change their locus of control-in most cases they become more internals than they used to be. The study also revealed that the external locus of control was substituted by the internal one. Such a change of the locus of control results in taking more personal responsibility for fulfiling the recommendations given by professionals from medical sphere. Consequently, psychological recommendation will involve promoting the qualities which are characteristic for internals. We suppose that obtained results will help us to develop the strategies for psychocorrection and psychorehabilitation during pandemic and post-pandemic period.

Keywords: COVID-19 pandemic, locus of contol, Rotter Test and its modified version. 